Provided for non-commercial research and education use. Not for reproduction, distribution or commercial use.

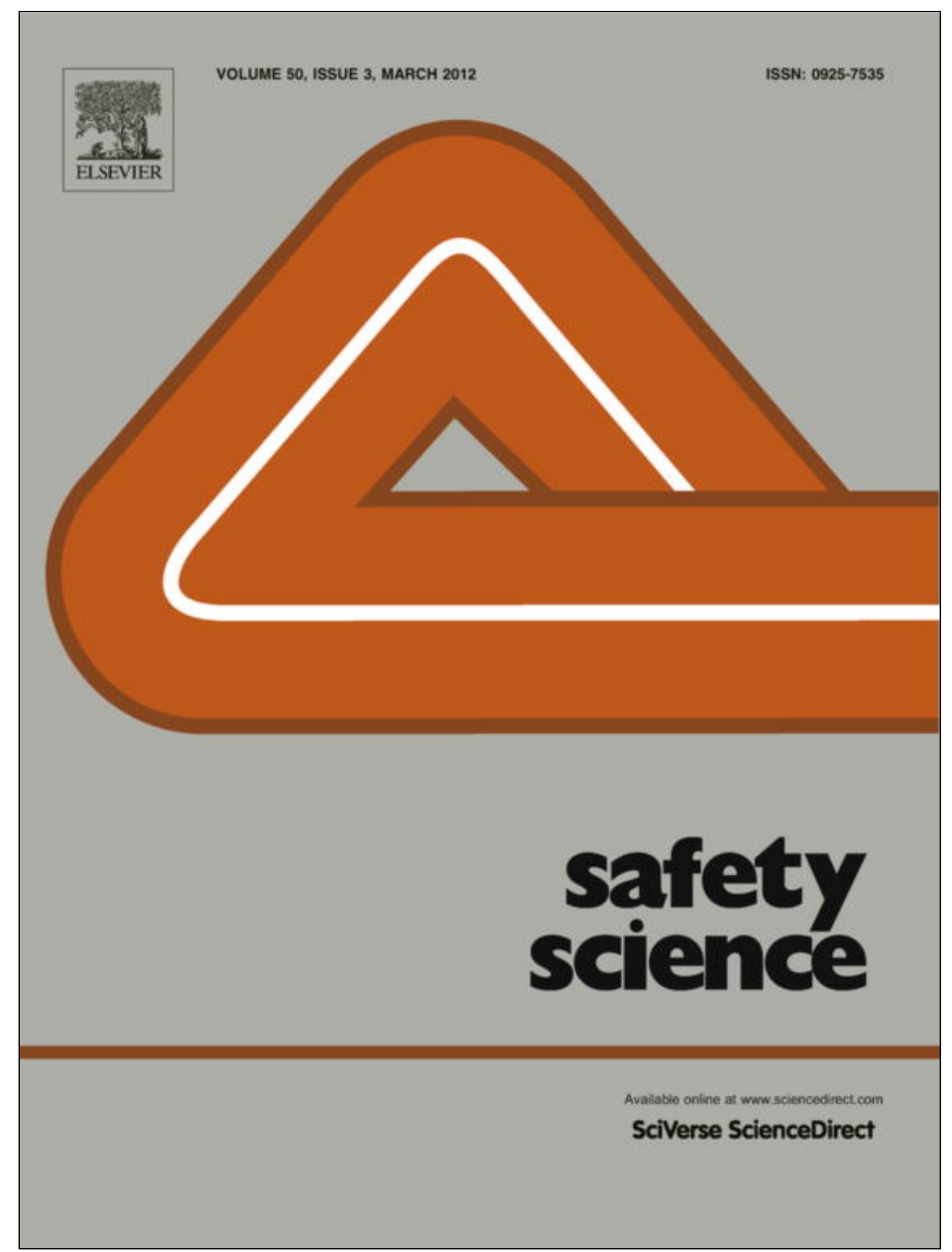

This article appeared in a journal published by Elsevier. The attached copy is furnished to the author for internal non-commercial research and education use, including for instruction at the authors institution and sharing with colleagues.

Other uses, including reproduction and distribution, or selling or licensing copies, or posting to personal, institutional or third party websites are prohibited.

In most cases authors are permitted to post their version of the article (e.g. in Word or Tex form) to their personal website or institutional repository. Authors requiring further information regarding Elsevier's archiving and manuscript policies are encouraged to visit:

http://www.elsevier.com/copyright 


\title{
Operator competence and capacity - Lessons from the Montara blowout
}

\author{
Jan Hayes* \\ School of Sociology, Research School of Social Science, The Australian National University, Canberra, ACT 0200, Australia
}

\section{A R T I C L E I N F O}

\section{Article history:}

Received 30 May 2011

Received in revised form 1 September 2011

Accepted 17 October 2011

Available online 15 November 2011

\section{Keywords:}

Blowout

Organisational accident

Barriers

Oil industry

Safety legislation

\begin{abstract}
A B S T R A C T
The blowout of the Montara H1 well in the Timor Sea off the northwest coast of Australia in August 2009 was the first such incident in Australian offshore waters for 25 years. This article seeks to draw lessons for management of complex hazardous activities from these events by analysing critical decisions regarding well control barriers. Concepts such as trial and error learning, sensemaking and the need for multiple barriers are used to demonstrate why the organisation was blind to the developing problems and hence why lack of technical competence alone is not sufficient to explain the events that occurred. Three organisational improvements are proposed - providing active supervision, improved technical integrity assurance and better use of risk assessment. The article concludes with an appeal for changes in regulatory policy regarding safety to include organisational issues in addition to the traditional technical focus.
\end{abstract}

(c) 2011 Elsevier Ltd. All rights reserved.

\section{Introduction}

The continental shelf off the northwest coast of Australia holds rich reserves of oil and gas with hydrocarbon exploration and production activities in the area stretching back over decades. On 21st August 2009, those in charge of drilling the Montara H1 oil and gas well in this area lost control of the well resulting in a blowout. People were successfully evacuated from the nearby facilities (platform, drilling rig and construction vessel) and there were no significant injuries or deaths associated with the incident, but uncontrolled hydrocarbons flowed into the environment for 75 days before the well was plugged.

Loss of well control incidents, commonly known as blowouts, are a well-known hazard in the offshore oil and gas industry. There were 39 blowouts on the US Outer Continental Shelf in the period 1992-2006 (Izon et al., 2007). The Australian offshore industry had also experienced six blowouts prior to Montara, with the immediately previous one being in 1984 (Borthwick, 2010). Whilst the impact of the Montara blowout was relatively limited, the Deepwater Horizon blowout in the Gulf of Mexico only 8 months later has acted as a graphic reminder (if it were required) of the damage that such incidents can cause.

Given the potential for disaster, and because of the large sums of money involved, drilling and well construction activities in this global industry are tightly controlled, both within operating companies and by regulation. How is it then that, in 2009, the Australian offshore industry can experience an incident like the Montara

\footnotetext{
* Tel.: +61 2 61252140; fax: +61261252222.

E-mail addresses: janhayes@bigpond.net.au, jan.hayes@anu.edu.au
}

blowout? The circumstances surrounding the incident provide valuable lessons for regulatory policy makers and others responsible for managing complex systems.

\subsection{Aims and theoretical foundations of the analysis}

This article describes an analysis of the casual factors surrounding the incident. It is based on an organisational view of accident causation, in particular the Swiss cheese model of Reason (1997). In this view of accidents, the errors of individuals in the field are linked to workplace causal factors which, in turn, are linked to organisational causal factors. These factors are also the source of latent errors which create dormant problems in systems designed to act as defences.

The aims of the work are twofold. Firstly, the analysis aims to describe this single case study in a way that allows broader lessons to be learned by those responsible for design, operation or supervision, not just in offshore drilling operations, but in any organisation that operates complex socio-technical technology. In seeking to interpret the specific events on Montara in these broader terms, the work draws on the tradition of high reliability theory (Bourrier, 2011) which highlights the common organisational factors that are relevant to managing such activities despite differences in technology. Further, the use of case studies has a strong tradition in both social science (Flyvbjerg, 2001) and learning by experienced people (Dreyfus and Dreyfus, 1986). This approach is based on the premise that by engaging with complex descriptions of case study material, people can see their own experience in a different light. In the context of prevention of complex accidents, the ultimate aim is for decision makers to see the potential for failure in their own 
particular circumstances (and hence take a different course of action) as a result of their reflection on the events on Montara.

Secondly, this analysis seeks to draw some conclusions about the effectiveness of offshore safety regulatory policy as highlighted by this incident. Safety cases were first introduced to the Australian offshore oil and gas industry following the Piper Alpha disaster in the UK sector of the North Sea in 1987 which resulted in 167 fatalities and the complete loss of the facility (Cullen, 1990). In 2009, for historical reasons, well integrity was regulated outside the main Australian safety case regime although the requirements of the well integrity regulations are based on the same goal setting approach. In this case, the regulations failed to prevent an accident. This analysis discusses the implications of the incident for future directions in regulatory policy.

\subsection{Sources, assumptions and scope}

The primary source document is the Report of the Montara Commission of Inquiry (CoI) (Borthwick, 2010), supplemented by the publicly available documents, submissions and witness statements made available by the CoI. ${ }^{1}$ The key individuals involved are the offshore Drilling Supervisors and Senior Drilling Supervisors. They reported collectively to the onshore Drilling Superintendent, who in turn reported to the Well Construction Manager. These individuals are all representatives of PTTEP Australasia (Ashmore Cartier) Pty Ltd. (known as PTT).

PTT holds the Production Licence for Montara, but the drilling work was conducted using a contract jack-up rig, the West Atlas, owned by Atlas Drilling. Whilst Atlas personnel should have played an important part in safety-related activities on the rig (in accordance with the facility Safety Case), in practice, they had only an indirect role in the actions surrounding the blowout. Similarly, Halliburton acted as a specialist subcontractor to PTT in relation to cementing activities and the Halliburton technician was involved in the cementing of the casing shoe (described at length below) but the overall sequence of events was driven by PTT. The CoI found that the role of both contractors was limited. Since the focus of this paper is on the competence and capacity of PTT as the operating company, details of actions taken by contractors are not covered in any detail here.

Similarly, it needs to be acknowledged that PTT gained control of the Montara Production Licence by acquiring the assets of Coogee Resources (a small, privately owned company) only months before the incident (in February 2009). Most of the people involved and the systems under which they were working were similarly carried over from the Coogee ownership. The impact of this transition and the extent to which operations at Montara had (or had not) been influenced by PTT's broader corporate experience were not issues that were investigated in detail by the CoI. Due to the limited evidence available on these issues, they have also not been addressed here.

It should be noted that this paper describes technical aspects of well construction activities only in sufficient detail to allow an accurate assessment of human and organisational issues related to the decisions made. As such, it focuses on the actions of PTT personnel primarily in comparison to the existing company standards. It is beyond the scope of this paper to evaluate those standards from a technical perspective. Whilst the CoI found that if PTT had operated in accordance with their own standards it is likely that the blowout would not have occurred, it should be noted that the CoI was also critical of some aspects of those standards.

In Australia, offshore safety is regulated under a goal setting, safety case style regime. At the time of the blowout, the relevant reg-

${ }^{1}$ See http://www.montarainquiry.gov.au/. ulations were administered by the Northern Territory Department of Resources (NT DoR) on behalf of the Australian Commonwealth Government. The institutional arrangements consisted of a single technical person reviewing submissions. ${ }^{2}$ The NT DoR had previous dealings with PTTEPAA and "regarded PTT as a good operator". ${ }^{3}$ The Col has made various recommendations regarding changes to regulatory arrangements and, as a first step, responsibility for well integrity has moved to the National Offshore Petroleum Safety Authority (NOPSA) as of mid 2011. Other regulatory changes have also been proposed as a direct result of the events surrounding Montara, but it is beyond the scope of this paper to discuss them in any detail.

The analysis of the Deepwater Horizon incident (National Commission on the BP Deepwater Horizon Oil Spill and Offshore Drilling, 2011) has focussed substantially on the fact that the well was being drilled in deep water which meant that there were significant new technical challenges to be addressed. This was not the case at Montara - the water depth at the facility is approximately $77 \mathrm{~m},{ }^{4}$ meaning that this well cannot reasonably be classified as a deep water well.

This analysis provides an assessment of the actions of the people offshore and their immediate supervisors within PTT, the choices they made and the organisational circumstances that prevailed. Actions of contractors, the regulator and the previous owner are not considered. This is necessarily a simplification and this article therefore does not present a full causal analysis of the incident. Nevertheless, given PTT's primary responsibility for the facility, the aims of the analysis stated in Section 1.1 can reasonably be achieved with this more limited review.

\subsection{Structure of the analysis}

The structure of this article adopts the general form of the Reason model (as described in Section 1.1) or of Rasmussen's Accimap (Rasmussen and Svedung, 2000). Section 2 provides a description of the incident itself. Section 3 addresses the immediate causes of the blowout with the following sections moving further away from the immediate circumstances. Decisions made in the workplace that led to those events are addressed in Section 4, and Section 5 analyses the possible causes of those decisions. Section 6 proposes some organisational improvements that may have prevented these issues from developing. Section 7 touches on the broader implications for safety regulatory policy in the Australian offshore oil and gas industry and Section 8 provides some concluding comments.

\section{The incident}

The Montara Wellhead Platform (WHP), owned and operated by PTTEPAA (known as PTT), was located in the Timor Sea, $250 \mathrm{~km}$ off the northwest coast of the Australian continent. Well H1 was drilled from the West Atlas jack-up drilling rig in March 2009.

This well was part of PTT's batch development drilling program for Montara, which included plans to drill five wells between January and April 2009. The plan was for the rig to leave the field at that time so that the WHP topside facilities could be installed (using the construction vessel the Java Constructor), and then to return in August to tie back the wells to the Montara WHP topsides. The measures to leave the well in a safe state between these two phases of work were defined by PTT's Well Construction Standard (WCS), although none of these measures were put in place in accordance with this standard. As described in the following

\footnotetext{
2 Borthwick, 2010, p. 16.

3 Borthwick, 2010, p. 15.

4 Borthwick, 2010, p. 49, paragraph 3.5 .
} 
sections, some requirements were simply ignored and others were not met adequately.

As planned, activity moved back to the $\mathrm{H} 1$ well in August 2009 when the West Atlas returned to the field. In preparation for further work, a pressure-containing cap was removed. Despite the fact that there was no significant pressure recorded under the cap prior to its removal, the blowout occurred within hours. Initially, the leaking fluids did not ignite. Oil and gas flowed for more than 10 weeks before a relief well was successfully put in place. The drilling of the relief well coincided with the ignition of the release. The resulting fire continued for a further 2 days before the flowing fluids were brought under control on 3 November 2009 and the fire extinguished due to lack of fuel. A month later, the well was finally declared safe.

No-one was injured or killed as a result of this incident. It has to be said that this is more good luck than good management and that, if the blowout had ignited immediately, the result could have been similar to the Deepwater Horizon incident which resulted in 11 fatalities and many injuries. At the time of the blowout, the construction vessel the Java Constructor was located close to the facility. As photographs taken at the time show vividly, if the gas cloud had ignited immediately, it is likely that the crew of the vessel (as well as those on the drilling rig itself) could have been adversely impacted.

Apart from the loss of the drilling rig and the platform due to the fire, the adverse physical consequences of the Montara event relate to environmental pollution and, even in this area, luck has played a part. Given the light nature of the escaping fluids and the remote location of the well, by far the majority of the hydrocarbon has simply weathered away and relatively little has impacted the Australian coast or marine life. ${ }^{5}$

\section{The immediate causes of the blowout}

Before looking at the details of the various decisions made regarding well control, this section summarises the flaws in the various well control barriers that, according to PTT's documentation, should have been in place to prevent a blowout but for various reasons were not.

At the time of the incident, the $\mathrm{H} 1$ well was in the development drilling phase. The well had been drilled and two casing strings set - an outer $133 / 8^{\prime \prime}$ casing to a depth of $1640 \mathrm{~m}$ and an inner $95 / 8^{\prime \prime}$ casing to a depth of approximately $3800 \mathrm{~m}$. The detailed sequence of events that led to the blowout starts with the cementing of the casing shoe at the bottom of the $95 / 8^{\prime \prime}$ casing.

PTT's Well Construction Standards (WCS) required two proven barriers to uncontrolled flow from the reservoir to the surface to be in place when the well was suspended. ${ }^{6}$ The primary pressurecontaining barrier should have been the cemented casing shoe at the end of the $95 / 8^{\prime \prime}$ casing (which was close to horizontal at that point). Based on the pressure and flow profiles seen during the cementing operation, it is apparent that the integrity of the cement was never proven and in fact that the outcome was a "wet shoe" with the cement contaminated by drilling and/or reservoir fluids.

Secondary barriers that should have been in place (according to the final well design) were two pressure containing corrosion caps (PCCCs). The well design called for these to be installed on the top

\footnotetext{
${ }^{5}$ Borthwick, 2010, p. 26. Whilst the environmental impact of the Montara blowout is limited compared to the Deepwater Horizon incident, there have been impacts felt in West Timor and the Commission of Inquiry has highlighted that the lack of baseline data and the slow response in putting a monitoring plan in place mean that the full extent of the impact of the Montara spill will never be known.

${ }^{6}$ PTTEPAA Well Construction Standard Section 5 reproduced in Statutory Declaration of P.J. O'Shea paragraph 105, Statutory Declaration of C.A. Wilson paragraph 130 and Statutory Declaration of L.S. Wishart Paragraph 135.
}

of both the $95 / 8^{\prime \prime}$ string and the outer $133 / 8^{\prime \prime}$ string. In fact, only one was installed (on the $95 / 8^{\prime \prime}$ string). Information from the manufacturer of the caps indicates that these are not designed as well control barriers and yet PTT chose to use them for this purpose. ${ }^{7}$ The $95 / 8^{\prime \prime}$ PCCC was later removed for operational reasons and then not re-installed. The blowout occurred approximately 15 hours later.

Another form of well control barrier is to ensure that the well is always in overbalance i.e. that the hydrostatic head of fluid in the well bore always exceeds the reservoir pressure and hence the well pressure balance will prevent fluid from flowing up the well bore to the surface. In the case of Montara, it seems to have been assumed by everyone involved that the well was overbalanced but this was not the case. Monitoring of the fluid in the well bore to ensure a sufficient safety margin in the bottom hole pressure had not taken place.

In summary, the various barriers to flow from the well that should have been in place prior to the blowout, and their status, are shown in the following table.

\begin{tabular}{cll}
\hline Barrier & $\begin{array}{l}\text { Testing/ } \\
\text { monitoring }\end{array}$ & Status \\
\hline $\begin{array}{c}\text { Cemented } 9 \\
5 / 8^{\prime \prime} \text { casing } \\
\text { shoe }\end{array}$ & $\begin{array}{l}\text { Not tested }- \\
\text { assumed to be } \\
\text { adequate }\end{array}$ & Ineffective \\
$133 / 8^{\prime \prime}$ PCCC & $\begin{array}{l}\text { None }- \text { not } \\
\text { installed }\end{array}$ & Not present \\
$95 / 8^{\prime \prime}$ PCCC & $\begin{array}{l}\text { Not integrity } \\
\text { tested when }\end{array}$ & $\begin{array}{l}\text { Not designed as barrier for } \\
\text { blowout. Removed prior } \\
\text { to blowout }\end{array}$ \\
installed & $\begin{array}{l}\text { Not monitored - } \\
\text { Ineffective } \\
\text { assumed to be } \\
\text { adequall fluids }\end{array}$ & \\
\hline
\end{tabular}

Ultimately, when the reservoir pressure was sufficient to overcome the column of fluids in the well bore, hydrocarbons were able to flow to the surface due to failure of the $95 / 8^{\prime \prime}$ cemented casing shoe. This was the only physical barrier to flow that was present on the well at the time the blowout occurred. ${ }^{8}$ The choices made in the months leading up to the blowout introduced a series of latent failures into the system of multiple barriers, hence negating the entire design philosophy and leaving the system in a very vulnerable state. Under these circumstances, uncontrolled flow of hydrocarbons to the surface was inevitable.

\section{Flawed decision making}

This section describes some of the decisions that were made about each well control barrier, and looks for understanding in the evidence given by individuals as to why they apparently considered at the time that the situation was sufficiently safe. The purpose is not to lay blame, but to seek to understand why such choices were made so that future decision making in similar situations can be improved.

\subsection{Misunderstandings about cementing}

Cementing is generally understood to be a safety critical activity in well construction. Cemented shoes, cement plugs and similar devices are used as primary well control barriers and cementing problems contributed to 18 of 39 blowouts on the US Outer Continental Shelf in the period 1992-2006 (Izon et al., 2007).

\footnotetext{
${ }^{7}$ Borthwick, 2010, p. 7

8 Borthwick, 2010, p. 7
} 
In the $\mathrm{H} 1$ well design, the device at the bottom of the casing that was intended to prevent communication from the reservoir to the surface was known as a casing shoe. The shoe and the surrounding space are designed to be filled with cement which, when set, provides a barrier to flow in both the casing and the annulus (the space between the casing and the well bore itself). During cementing operations for the $\mathrm{H} 1 \mathrm{well}$, the intention was that a volume of cement sufficient to fill both the well bore and the annulus to the appropriate depth was pumped into the well. The casing shoe arrangement includes two float valves i.e. one-way valves designed to prevent flow backwards from the casing shoe up the well bore. These devices could perhaps be thought of as a separate barrier to flow from the reservoir to the surface but since they cannot be independently tested they have been considered here as integral to the cemented shoe. The cement pumping operation also included the running of two spacer plugs into the casing, one before and one following the cement itself. One function of these devices is to provide feedback on what is occurring down hole. The location of the spacer can be confirmed by a "bump" or spike in the pressure as the second spacer reaches the top of the casing shoe.

In accordance with the drilling plan, a pressure test to confirm the integrity of the casing above the cemented shoe was conducted once the cement plus associated plugs were in place. Constant pressure could be maintained in the system during the test, but at the conclusion of the test, when the pressure was reduced, 16.5 barrels of fluid were returned from the casing string and, after the system was bled down, the pressure started to increase again. This indicates some leakage of fluid back through the float valves. The well was initially shut in and then it was decided by PTT personnel offshore that the best way to fix this problem was to pump the extra fluid back into the well. Those involved have provided no explanation as to why they thought that this was an appropriate response. Pumping fluid back into the well at that stage would necessarily force fluid back through the float valves into the shoe, creating the possibility of what is known as a "wet shoe" i.e. contaminating the cement with hydrocarbons and/or inhibited seawater from higher up the casing. Those involved failed to recognise this possibility or the potential consequences of their actions. Cement that is contaminated with other fluids can provide channels or pathways for flow of hydrocarbons and is therefore lacking in sufficient integrity to act as a well control barrier.

After pumping the additional fluids back into the well, the next step taken was to maintain pressure on the well and then wait on the cement to set. Critically, no additional tests were done to confirm the status of the float valves or the integrity of the cemented shoe. This would have required a negative pressure test (or inflow test) where the pressure in the casing above the cemented shoe was reduced (rather than increased) in order to test whether the float valves hold when the pressure differential across them is reversed. The fact that PTT's WCS required two separate tests - a positive pressure test to confirm the integrity of the casing followed by a negative pressure test to confirm the integrity of the float valves - does not seem to have been recognised by those involved at the time.

Effective well integrity tests are not simply a matter of completing a series of steps. Qualified people must make mindful decisions regarding the meaning of the results. The course of action taken following on from a test would then depend critically on both seeing and interpreting these results. In this case, there seems to have been no active consideration of the results. The tests were apparently considered by those involved as activities that needed to be completed, but not as decision points that could change the sequence of subsequent activities. In this way of thinking about the tests the results become irrelevant as the objective is to complete the work and move on. This is discussed further in Section 5.2 .

\subsection{Modifications to the suspension plan for well H1}

Other barriers that should have been in place according to the approved well design at the time of the incident were the PCCCs.

PTT's original well design for $\mathrm{H} 1$ included a shallow set cement plug as a barrier to flow from the well during the April to August period when the drilling rig was absent. ${ }^{9}$ During the first phase of activity, PTT requested and received permission from the regulator at very short notice to change the well design to replace the cement plug with pressure containing corrosion caps (PCCCs) over two casing strings. ${ }^{10}$ The decision to replace the cement plug with two PCCCs was documented in a formal Well Construction Change Control Form prepared by the Drilling Superintendent and approved by the Well Construction Manager. ${ }^{11}$ The change control form includes fields to record both the HSE impact and the cost impact of the proposed change. In this case, the HSE impact is described as "improved well integrity during suspension and re-entry operations". The cost impact is noted as "savings of up to US\$50,000 in rig time" with the basis of the saving noted. Thus the author is proposing not a trade-off between safety and cost, but improvements in both areas.

The change control form provides no information as to why the author was of the opinion that PCCCs would provide a higher degree of well integrity than a cement plug. Some explanation is provided by PTTEPAA in a submission to the Col which states that the considerations for the amendment to the Drilling Program were as follows:

(a) pressure containing corrosion caps allow pressure below the cap to be checked prior to removal, whereas cement plugs do not;

(b) the risk of damaging the casing when drilling out a cement plug; and

(c) a $95 / 8^{\prime \prime}$ pressure containing corrosion cap was available. ${ }^{12}$

The PTTEPAA Well Construction Standard (WCS) requires "two permanent tested barriers" 13 for a long term suspension such as the planned April to August gap in the Montara drilling program. Details of those items that can be legitimately classed as permanent barriers emphasise the need for integrity testing and include "pressure tested cement plug ( $\min 30 \mathrm{~m}$ in length)" and "cemented casing with proven [top of cement]". The list does not include PCCCs.

The Well Construction Manager, Drilling Superintendent and one of the Senior Drilling Supervisors maintain that PCCCs are essentially the same as tubing seals which are an allowable permanent barrier in the WCS. ${ }^{14}$ Another Senior Drilling Supervisor claimed that PCCCs are superior to cement plugs (another allowable permanent barrier). ${ }^{15}$ In fact, as will be discussed further in Section 6.3, the vendor of the PCCCs advises that they are not designed to be used as a device to prevent flow from a well.

Even accepting that PCCCs were an acceptable well control barrier, the installed integrity of the devices would need to be tested in order to meet the requirements of the WCS. Critically, the scope

\footnotetext{
${ }^{9}$ Statutory Declaration by N.E. Treasure paragraph 13.

10 Borthwick, 2010. See paragraph 3.9.

11 The form is reproduced as Appendix 5 to the Montara H1 ST1 Well Release Incident Report Rev 0 by PTTEPAA dated 2 October 2009.

12 PTTEPAA Submission \#1 to Col paragraph 105.

13 PTTEPAA Well Construction Standard Section 14 reproduced in Statutory Declaration of P.J. O'Shea paragraph 107, Statutory Declaration of C.A. Wilson paragraph 132, Statutory Declaration of C.N. Duncan at paragraph 140 and Statutory Declaration of L.S. Wishart Paragraph 137.

${ }^{14}$ See Statutory Declaration of C.N. Duncan at paragraph 151, Statutory Declaration of C.A. Wilson paragraph 143 and Statutory Declaration of P.J. O'Shea paragraph 118

15 See Statutory Declaration of N.E. Treasure Paragraph 12.
} 
change as written contains no information about testing of the integrity of the caps when installed although (as detailed in Section 6.3) PTT onshore management/technical personnel claim that they expected such tests to be carried out.

The Col had no hesitation in rejecting PTT's argument that this change to the well design was made for reasons of well integrity. ${ }^{16}$ The decision appears to have been made in order to reduce costs, with minimal consideration of the need to ensure the integrity of the barrier or the potential consequences of failure of the barrier. As described in the following sections, the impact of this change was further compounded by the casual way in which the installation of the PCCCs was managed.

\section{3. $133 / 8^{\prime \prime}$ PCCC not installed}

As described in Section 3, the drilling program was changed so that the cement plug was replaced in the well design by two PCCCs, only one of which was subsequently installed. In this way, an industry-standard well control barrier was replaced by a single lesser barrier performing a function for which it was not designed.

Whilst the final approved well design calls for a 13 3/8" PCCC as a barrier to be put in place when the well was suspended in March 2009, it was discovered, when the West Atlas returned and work on the $\mathrm{H} 1$ well was due to recommence in August, that this PCCC had never been installed. The details of why this occurred are unclear although some conclusions can be drawn from the available evidence.

One of the PTT Senior Drilling Supervisors has described why the $133 / 8^{\prime \prime}$ cap was not installed when work on the H1 was initially suspended. The reason he gives is that the $\mathrm{H} 1$ well was going to be used in coming weeks as a place to "park" the blowout preventer (or BOP) for operational convenience as required during other activities. ${ }^{17}$ This downgrades the function of the PCCC from an important and necessary well control barrier to something that could be installed at some unspecified point in the future as a matter of operating convenience.

The Senior Drilling Supervisor noted that the need to install the PCCC on the $133 / 8^{\prime \prime}$ string was listed as an outstanding job on a white board in the Drilling Supervisor's office. ${ }^{18}$ At the time that the final stages of the suspension work on the $\mathrm{H} 1$ well were completed, various reports were sent onshore reporting that the PCCC had been installed. Because the $20^{\prime \prime}$ trash cap was installed over the top of the location where the PCCC should have been installed, it was not possible to observe after the event whether the work had actually been completed, but it appears everyone assumed that it had been done, despite the fact that the cap itself (supposedly an important piece of safety equipment) was subsequently returned to the supply base in Darwin. ${ }^{19}$

PTT's preliminary investigation into the incident published in October 2009 states: "PTTEPAA's investigation of this incident has determined that, in March 2009, personnel on the [rig] discovered that a valve in the cap designated for use in the H1 Well was rusted up. It would appear that this is the reason why the cap was not installed in the well. The Drilling Superintendent was however advised by the Drilling Supervisor on the [rig], in an email advice of offline activities at the time of the March 2009 suspension, that the cap was installed". ${ }^{20}$

\footnotetext{
16 See Borthwick, 2010, p. 11.

17 Statutory Declaration by N.E. Treasure paragraph 28. The BOP is not functional on the $\mathrm{H} 1$ well during these operations; it is simply physically located there whilst activities on other wells are carried out.

18 Statutory Declaration by N.E. Treasure paragraph 32.

19 Borthwick, 2010. Paragraph 3.284.

20 Montara H1 ST1 Well Release Incident Report Rev 0 by PTTEPAA dated 2 October 2009.
}

Contrary to this statement regarding the unserviceable state of the 13 3/8" PCCC, all PTT personnel who later supplied statutory declarations to the CoI deny any direct involvement in this issue and express surprise that the device was not in place. ${ }^{21}$

It is not possible to know with any certainty who first stated incorrectly in a written report that the $133 / 8^{\prime \prime}$ PCCC had been installed, and who simply repeated that information without physically confirming the installation. It is clear however that the installation of the device was treated by all involved as relatively unimportant from a safety perspective (given the delay in installation and the casual way in which the work was stewarded). Also, as described in Section 4.2, the cost saving in moving to PCCCs was substantial $-\$ 50,000$ in rig time. If the PCCC was found at the last minute to be unserviceable (for example due to a rusty valve) and there was a need to change the plan back to a cement plug, this would apparently have resulted in that expenditure of $\$ 50,000$ being incurred. Under these circumstances, it is hardly surprising that a decision might be made on the run by one or more people offshore to simply ignore the requirement for the PCCC altogether.

\subsection{Removal of the $95 / 8^{\prime \prime}$ PCCC and failure to re-install it}

Unfortunately the failure to install the $133 / 8^{\prime \prime}$ cap had other consequences. The threads inside the top of that casing string had been unprotected and hence were found to have corroded when the work recommenced on the H1 well in August. The $95 / 8^{\prime \prime}$ PCCC that had been installed when the well was suspended in April was then removed to allow cleaning of the threads at the top of the $133 / 8^{\prime \prime}$ casing. This course of action was discussed between onshore and offshore PTT personnel and the ultimate decision was made by the Well Construction Manager (who was on West Atlas at the time).

Prior to removal of the cap, pressure measurements indicated no trapped hydrocarbons and no visible hydrocarbons were observed when the cap was removed. This was seen by those involved (including the Well Construction Manager) as an indication that the well was stable and therefore that other barriers (such as the casing shoe and the fluid overbalance) were adequate. ${ }^{22}$ In fact, since the integrity of the seal of the $95 / 8^{\prime \prime}$ cap on the casing had never been tested, the fact that no significant pressure was recorded does not rule out the presence of hydrocarbons from the reservoir. Following work to clean the threads on the $133 / 8^{\prime \prime}$ casing, the $95 / 8^{\prime \prime}$ cap was not replaced and the derrick was skidded to another well. There was no ongoing monitoring of the status of the $\mathrm{H} 1$ well whilst the main focus of activity was on another well.

Since the $133 / 8^{\prime \prime}$ PCCC had not been installed as planned and this had apparently resulted in no undesirable side effects between April and August, perhaps it is not surprising that the $95 / 8^{\prime \prime}$ PCCC was also not seen as a critical safety device. Not reinstalling the 9 $5 / 8^{\prime \prime}$ cap saved some rig time and was seen as acceptable based on the earlier pressure observations and because this arrangement apparently complied with PTT's standards which had changed now that the rig had returned.

Once the West Atlas rig returned to the facility and well operations were planned to recommence, the requirements for well control barriers could be legitimately revised according to the PTT WCS. If the well status is classed as a temporary suspension with a MODU on location, the requirement for "tested, independent barriers" 23 then

\footnotetext{
$\overline{21}$ Statutory Declaration of N.E. Treasure paragraph 36, Statutory Declaration of C.A. Wilson paragraph 263, Statutory Declaration of C.N. Duncan at paragraph 356 and Statutory Declaration of L.S. Wishart Paragraph 237.

22 Statutory Declaration of L.S. Wishart paragraph 242 (a) and Statutory Declaration of C.N. Duncan Paragraph 246.

23 PTTEPAA Well Construction Standard Section 5 reproduced in Statutory Declaration of P.J. O'Shea paragraph 105, Statutory Declaration of C.A. Wilson paragraph 130, Statutory Declaration of C.N. Duncan paragraph 138 and Statutory Declaration of L.S. Wishart Paragraph 135.
} 
becomes a single permanent barrier or two temporary barriers. In this case, cemented casing is listed as a permanent barrier (if it has been tested). Hydrostatic pressure of fluid in the well is an allowable temporary barrier "provided that liquid level and density is monitored and maintained".

Of course in practice the cemented shoe had not been tested and was not an adequate barrier. As described in the following section, the hydrostatic pressure balance was also not to be relied upon.

\subsection{Reliance on overbalance}

The discussion so far has related to physical barriers specifically installed to prevent flow of reservoir fluids up the wellbore to the surface. The other way to prevent fluids from flowing up the well is to ensure that, at all times, the weight (or hydrostatic head) of fluids in the wellbore always exceeds the reservoir pressure at the bottom of the well so that there is no driving force for flow to the surface. A well in this state is called "overbalanced".

In the case of Montara, evidence was given that the well design was based on a reservoir pressure that was "normal" - in other words equivalent to the same depth of seawater. ${ }^{24}$ This important design data was provided by PTT's geologist. ${ }^{25}$ This in itself is unusual as such design data would more commonly be generated by a reservoir engineer. PTT's standards required that, in order to rely on overbalance as a well control barrier, level and density of the completion fluid must be monitored and maintained. The WCS also requires a safety margin between the pressure exerted by the fluids in the wellbore and the maximum expected reservoir pressure. In the case of the $\mathrm{H} 1$ well, there was no monitoring of the level or density of the fluid and no consideration of the safety margin required to meet the WCS. Inhibited seawater was used as the wellbore fluid which by definition means that the pressure exerted by the column of fluid is essentially equal to the reservoir pressure, without the safety margin that is required by the WCS. Despite this, all PTT personnel apparently assumed that the well was safely overbalanced and that it was reasonable to "count" this as a well control barrier.

In summary, a series of poor decisions contributed to the creation of the unsafe situation at Montara and also the failure to recognise the state of the system. The following section describes some aspects of decision making across the organisation that contributed to this unfortunate state of affairs.

\section{Organisational blindness}

None of the individual failures described above is catastrophic or unprecedented. Even the most experienced and diligent individuals make errors on occasions, but well designed and managed systems have sufficient redundancy, along with the ability to identify and respond to individual errors, so that catastrophic consequences can be prevented. In the case of Montara, PTT was lacking such skills. This meant that the combination of so many poor individual decisions has had profound consequences.

This section focuses on two theoretical perspectives that illuminate some of the possible reasons for the decisions described in Section 4.

\subsection{The need for multiple barriers}

The preceding discussion has focussed at length on the need for multiple barriers to be in place in order to prevent uncontrolled

\footnotetext{
24 See Borthwick, 2010. Paragraph 3.229. There is also discussion about the exact specific gravity that is reasonably meant by "normal" and the possible range of the specific gravity of seawater, but the overall point discussed here remains valid.

25 Statutory Declaration of C.N. Duncan Paragraph 114.
}

flow from the well. There are many terms for the safety management philosophy of having multiple barriers in place, as this concept is widespread in engineering and not confined to well operations. Engineers tend to talk about system redundancy or defence in depth (Hollnagel, 2004). This is a common risk management principle for systems where the consequences of failure are very significant and/or environmental uncertainties mean that the reliability of individual barriers can be uncertain. Specifically, it is also normal practice in well control as described in various submissions to the Inquiry. ${ }^{26}$ Reason's Swiss cheese model is a broader statement of a similar concept from the organisational safety literature, reminding us that defences always have "holes" like Swiss cheese and so multiple defences are always needed to be confident that undesirable outcomes can be prevented (Reason, 1997).

It appears that, at Montara, those involved in the field did not think about either the well design or their activities in such terms. Their assumption seems to have been that, provided any single barrier was in place, it was reasonable to assume it was $100 \%$ reliable and that the system was safe enough. On that basis, further barriers could be treated as optional and not really necessary, especially if the associated cost was significant. Based on this attitude, the integrity of the well moved incrementally to a less and less safe position. Starting from a design that called for two tested barriers, the design moved to one barrier that was imperfect and yet untested (the cemented shoe), and two PCCCs called on to perform a function for which they were not designed. Ultimately, the PCCCs were either not installed at all or not tested and then ultimately removed.

The barriers concept also reinforces the idea that any incident is the result of multiple failures, probably occurring over an extended period of time, and should not be linked simply to the event that triggers the final accident sequence. One of the Drilling Supervisors shows his lack of understanding of this aspect of such an approach when he states: "The absence of the 13 3/8" PCCC did not cause the uncontrolled release. In the context of the other barriers that I thought were in place, the H1 well was controlled even without the $133 / 8^{\prime \prime}$ PCCC. Even when the 9 5/8" PCCC was removed the H1 well was stable without the $133 / 8^{\prime \prime}$ PCCC."27 In fact, the well blew out some hours later, so this statement is demonstrably incorrect.

The same Drilling Supervisor also stated "The absence of pressure testing for the PCCCs on installation was not causative of the uncontrolled release. The PCCCs did not fail under pressure in any way." ${ }^{28}$ This is correct only in the narrow sense that both PCCCs were removed prior to the blowout, making irrelevant any discussion about tests. On the other hand, if the caps had been installed and pressure tested, then flow from the reservoir would have been unlikely to reach the surface (putting aside for the moment the fact that the manufacturer states that the caps were not designed for this purpose, they may indeed have limited or contained the flow had they been in place, and that was certainly PTT's position as to their functionality).

In order to prevent accidents, it is important for those with responsibility for the various barriers to understand the role of each barrier and the ways in which it might fail. These statements do not demonstrate such an understanding.

The Senior Drilling Supervisor also shows a similar attitude to multiple barriers when he indicates that, with the benefit of hindsight, perhaps he should have been aware of the problems experienced during the cementing of the $\mathrm{H} 1$ well, but he notes that "I could have reviewed the Halliburton cementing reports when

\footnotetext{
${ }^{26}$ See discussion of submissions by both the Western Australian and Victorian regulators in Borthwick, 2010. Paragraphs 3.195 and 3.196.

27 Statutory Declaration of L.S. Wishart paragraph 236.

28 Statutory Declaration of L.S. Wishart paragraph 235.
} 
I returned to the West Atlas on 26 March, 2009, but there was no need for me to do that at that time and not reviewing them so far after the cementing took place could not have caused the uncontrolled release". ${ }^{29}$

Of course if the problems with the cementing had been identified, even after the event, then there would have been an opportunity for further action to be taken. As is described in Section 5.2, a review of the available information by an appropriately experienced person would have revealed problems with the cementing to the point where it was clear that well integrity had not been proven and was likely to have been compromised. If this had been highlighted, even some time after cementing activities had nominally been completed, then further action could have been taken to ensure that well integrity was maintained, particularly when the rig returned and the PCCCs were removed in order to restart well activities.

It is possible that these individuals made these statements regarding the cause of the blowout in an effort to protect themselves as part of the legal proceedings in train at the time. Nevertheless, their actions prior to the incident show that PTT personnel had a general misunderstanding about the need for and role of multiple barriers in control of the potential for a blowout. The multiple barriers concept is ubiquitous in the oil and gas industry so it is not credible that the entire PTT team was unaware of this philosophy and yet they all failed to act in a way that was consistent with the need for multiple barriers. One possible explanation for this lies in the extent to which they were drawing on their own past experience, rather than any theoretical requirements, in acting as they did.

Learning from experience can be thought of as a process of trial and error (Argyris, 2004; Dreyfus and Dreyfus, 1986). Whilst this is a successful strategy in many ways, it can be dangerous when applied to complex system failures. Many people who work offshore may go through their entire career without being personally exposed to an incident of the type seen on Montara. One down side of this is that poor practices can become entrenched. As corners are cut and more holes develop in the Swiss cheese, there is apparently no down side. This leads to the adoption of a new norm which may continue to move incrementally away from the original design or organisational intent as more changes are made, all seemingly at no cost to safety. Our experience can fool us into believing that what we are doing and seeing is safe. This type of behaviour has been highlighted by Vaughan (1996) in relation to the catastrophic loss of the space shuttle Challenger. In this case, the shuttle was lost due to the failure of rubber solid rocket booster seals. Launches of the shuttle had moved progressively further away from the design operating conditions of the seals apparently with no penalty, until the seals ultimately failed and the shuttle was lost. Vaughan calls this "the normalisation of deviance".

Trial and error learning poses serious dangers as an approach regarding low frequency (but potentially high consequence) accidents. This has been highlighted by the high reliability organisation theorists who have emphasised the need to seek out and focus on small failures as opportunities for learning (Carroll et al., 2002; Weick and Sutcliffe, 2001). If the importance of such individual failures is not understood, then the failures are not reported or recorded in any way that allows them to be corrected or for similar situations to be avoided in the future (Hayes, 2009a). Lack of such a focus has a major detrimental impact on the organisational capacity to learn before a serious accident occurs as a result of the accumulation of small failures. Of course this argument also emphasises the importance of sharing detailed interpretations of specific events as we are doing by both writing and reading this article.

\footnotetext{
${ }^{29}$ Statutory Declaration of P.J. O'Shea paragraph 185 emphasis added.
}

As described in Section 4.2, cost was a strong driver for the changes to the well design and Section 6.1 describes feedback given to all those involved regarding savings resulting from cuts to the schedule. In an environment where feedback on cost and schedule is common and feedback on technical safety issues is weak or non-existent, it should not be surprising that a dangerous situation can develop, seemingly without anyone being aware of it.

\subsection{Seeing is believing?}

As described in Section 4, there were significant flaws in decision making related to Montara H1 well control barriers. All PTT personnel seemed to be of the view that, if a problem were developing, then they would get some clear warning which would be obvious even to people who were not actively looking for such warning signs. In fact, accident analysis usually demonstrates that accidents occur for the most banal reasons and that warning signs can be difficult to spot even for those who are actively looking for them. As the Baker panel report into the Texas City refinery fire reminds us (Baker, 2007): "Preventing process accidents requires vigilance. The passing of time without a process accident is not necessarily an indication that all is well and may contribute to a dangerous and growing sense of complacency. When people lose an appreciation of how their safety systems were intended to work, safety systems and controls can deteriorate, lessons can be forgotten, and hazards and deviations from safe operating procedures can be accepted. Workers and supervisors can increasingly rely on how things were done before, rather than rely on sound engineering principles and other controls. People can forget to be afraid."

It appears that PTT personnel had forgotten to be afraid.

In response to this situation, the $\mathrm{CoI}$ (and much of the industry response to the incident) has focussed on issues related to the technical competence of drilling personnel. The CoI found that PTT's drilling personnel (offshore and onshore) were "deficient in their decision making and judgements in relation to a number of important matters" and that "the magnitude of this failure reflected a failure of judgement and competence". ${ }^{30}$ Seeing the decisions only in those terms potentially limits our ability to learn something from the events on Montara.

Clearly, those responsible for complex and important activities need to have sufficient technical understanding of the work to complete it to an appropriate standard and yet lack of knowledge does not seem to provide an adequate explanation for the lack of action on the facility. At a recent industry summit into the response to Montara and Deepwater Horizon, one oil industry executive asked the rhetorical question: "why did experienced people fail to see at the time, the things that are so obvious to us now?" The concept of sensemaking provides a further possible insight into this apparently puzzling situation.

The view that this is primarily an issue of competence lies in the assumption that the failure is one of interpretation. Considering events in these terms leads us to conclude that evidence of problems with cementing (for example) was plain to see but was not acted upon because it was not interpreted correctly, or alternatively that decision making was flawed because the wrong choice was made.

A different view of the process of decision making is offered by the literature on sensemaking (Weick, 1995, 2001). Sensemaking "...is about the interplay of action and interpretation rather than the influence of evaluation on choice". (Weick et al., 2005, p. 409) Sensemaking includes the process of creating meaning from the entire ongoing flow of our experience. This perspective is useful in providing an answer to the question posed by the oil executive

\footnotetext{
${ }^{30}$ Borthwick, 2010, p. 9
} 
quoted above. Perhaps the people on Montara and the onshore managers did not take action, not because they failed to interpret the results of the tests but because they literally did not notice what was happening, even when the evidence was available to them. Several onshore specialists from PTTEPAA and Atlas received detailed reports on the cementing work (variously the Halliburton cementing report, the Atlas Daily Operations Report, the PTT Daily Drilling Report and the PTT cementing report). Each report included an account of the cementing activities that provided evidence that the integrity of the cement shoe was at best unproven and, in fact, most likely to have been compromised and yet all involved failed to extract those cues from the information available to them.

Only in hindsight did the Well Construction Manager and Drilling Superintendent acknowledge that it is most likely that the float valve failed in service (as should have been clear from the additional volume of fluid returned following the initial pressure test $)^{31}$ and that the subsequent strategy of pumping the extra volume back into the well most likely resulted in a "wet shoe" (as can be suspected from the pressure profile seen when the fluid was pumped back into the well, specifically the lack of a "bump" as the plugs re-seated). ${ }^{32}$ They also acknowledged that, contrary to the assertion in one drilling report that the float valves were retested, in fact there was no test done (as there was no reverse differential pressure across the valves that would have shown whether or not flow would be prevented). ${ }^{33}$ The onshore Drilling Superintendent concludes that "...the absence of another pressure test meant that, with hindsight and knowing what I know now, the integrity of the H1 Well was not verified". ${ }^{34}$ As the Well Construction Manager summarises, "...the facts about the cementing of the shoe float were contained in distributed reports to well qualified people (including me) but it appears that the circumstances did not call on anyone to analyse that information".35

Sensemaking is fundamentally about plausibility (Mills, 2003; Weick, 1993, 1995). If we believe something is true, then we fail to see evidence to the contrary. In this case, perhaps personnel involved with Montara believed that what they were doing was safe (based on their experience as described in Section 5.1). This belief directly impacts the cues that are extracted from a dynamic and complex work environment such as that involved with offshore drilling. It is not that seeing is believing, but rather that believing allows us to see what we might otherwise fail to recognise.

As a result, a decision maker is no longer seen to make a choice based on their individual judgement, but acts deterministically as a result of the sense that has been made of the situation, at that instant in time when action is initiated. Since sensemaking is also understood to be a social process, this broadens the focus in seeking explanations from individuals to the organisation. Snook (2000) makes this point when he uses sensemaking as one frame for his analysis of the accidental shooting of US Blackhawks over northern Iraq (which resulted in 26 friendly fire fatalities).

These factors - a lack of understanding of the need for multiple barriers, perhaps driven by trial and error learning and the sense people have made from their collective experience - taken together, have created the situation where the organisation is essentially blind to the serious safety problems that were developing. Understanding how this situation can arise is important when we are seeking to learn broadly applicable lessons from the specific events on Montara in order to prevent recurrence.

\footnotetext{
31 See Statutory Declaration of C.N. Duncan paragraph 303.

32 See Statutory Declaration of C.N. Duncan paragraph 327

33 See Statutory Declaration of C.N. Duncan paragraph 334

34 Statutory Declaration of C.A. Wilson paragraph 254

35 Statutory Declaration of C.N. Duncan paragraph 370.
}

The following section proposes some organisation improvements that address these issues.

\section{Some key organisational improvements}

As described in Section 5, complex systems require multiple barriers in place to ensure operations remain safe. Such systems also depend on those with responsibility for decision making to maintain their collective ability to recognise developing problems before they become critical. Decision making is not only about finding the right answer; in complex systems it is also critically about asking the right question. This is a key function of managers in their role as "sense givers" for the organisation (Weick, 1995, p. $10)$.

This section proposes three ways in which PTT management could have provided more effective leadership on these issues and thus have made an accident such as the blowout of the $\mathrm{H} 1$ well a much more remote possibility.

\subsection{Providing active supervision}

One of the most startling failures in the events leading up to the blowout is the failure to install the $133 / 8^{\prime \prime}$ PCCC followed by the reporting to onshore management that such a cap had indeed been installed. It is difficult to escape the conclusion that someone (indeed probably several people) knew that the cap had not been installed, and yet reported to onshore management that it was in place.

This event can perhaps best be considered as an indication of the relationship between offshore and onshore PTT personnel. The onshore management team appear to have taken a very "hands off" role in relation to work done offshore. In his statement to the CoI the PTT Drilling Superintendent stated that "if there was an issue with a forward plan that could not be resolved offshore [the Senior Drilling Supervisor] would call me to discuss the issue. The plans were not normally sent to PTTEPAA's office for review unless there was an issue that could not be resolved offshore. . .if the Senior Drilling Supervisor. . needed additional expertise from onshore staff, he would telephone me." 36 To emphasise this point, the attitude of onshore management was to assume that offshore personnel were competent and operating in accordance with approved standards, without ever conducting any checks as to whether this was actually the case.

The Drilling Superintendent also states that, with regard to checking the reports on cementing operations, he had no reason to check the reports in detail and that he "reviewed the DDR to see if there was any obvious errors or issues. There were none." ${ }^{37}$ As the CoI report points out, ${ }^{38}$ the role of the Drilling Superintendent was the day-to-day supervision of activities offshore, and this involves much more than simply looking for obvious errors in written summaries of work done, especially work involving a critical safety function such as the cementing of the casing shoe.

The Drilling Superintendent indicates again his overall attitude to supervision when he says "....as there were no indications or reasons after 21 April 2009 to think that the wells were not suspended per the DP and subsequent change control, there was no reason to conduct any form of audit to check that all work that was thought to be performed had in fact been completed..."39 Of course there was evidence available, particularly in relation to the state of the cemented casing shoe, if only he had looked.

The fact that critical activities were apparently conducted with no supervision is a key failing on the part of the organisation as a

\footnotetext{
${ }^{36}$ Statutory Declaration of C.A. Wilson paragraph 33.

37 Statutory Declaration of C.A. Wilson paragraph 185.

${ }^{38}$ Borthwick, 2010. Paragraph 3.123.

39 Statutory Declaration of C.A. Wilson paragraph 266 (c).
} 
whole. It should be emphasised that this is not a matter of considering that employees may be dishonest. The principle of active supervision is that employees take their cue as to what is important from what their superiors pay attention to, and further that people respond to positive reinforcement of appropriate behaviours. If no-one ever asks about well control barriers being in place or checks that integrity tests have been done in accordance with written requirements, then the message given is that these issues are not cues that need to be considered in deciding how work should proceed.

Looking in the statements provided by PTT management to see what was regarded as important reveals the following communication. Five days before the blowout, the Drilling Superintendent sent an email titled Montara Platform Wells Morning Update of 16 April to a wide range of people (including on rig personnel, senior PTT management in Thailand and government representatives) which states: "Whilst we have been busy drilling some our guys have been working offline to suspend Montara H3ST-1 and Montara H1. Both wells will be fully suspended by the end of the day. This has saved us about 12-18 h of rig time by being able to do this activity offline - a job well done". ${ }^{40}$

In these circumstances, it is not difficult to imagine a scenario in which the $133 / 8^{\prime \prime}$ cap was found at the last minute to be unserviceable (as PTT initially reported to the CoI - see Section 4.3) and offshore personnel decided to proceed with installation of the trash cap anyway and suspend the well without the additional barrier. It is perhaps significant that it is the Daily Drilling Report dated 17 April (i.e. the day after the above general note) from the offshore team to onshore management that first reports the fictional installation of the $133 / 8^{\prime \prime}$ PCCC. By sending such a report, the offshore personnel were simply confirming what onshore management wanted to hear.

\subsection{Separation of engineering integrity and operations functions}

Another unsatisfactory organisational feature revealed by the quotes from the Drilling Superintendent in the previous section is the level of technical discretion given to offshore personnel, in particular the lack of any engineering integrity function at PTT that was independent of line operations activity. To emphasise this point, this means that operational personnel were in control of whether or not engineering input was required, meaning that there was no separation between engineering integrity and operations functions. As is clear from the details of the cementing activity described in Section 4.1, the personnel responsible for conducting cementing operations offshore apparently had serious gaps in their technical ability to understand what was occurring offshore and to know at what point they needed to seek specialist advice. ${ }^{41}$

This situation appears to have its roots in the roles previously held by the various individuals involved. The Drilling Superintendent had previously (prior to the operational drilling phase) held the role of Senior Drilling Engineer. ${ }^{42}$ In that role, he had been responsible for (amongst other things) the design of the wells. Once the drilling program moved into the operational phase, he took on the role of Drilling Superintendent with all the PTT offshore drilling crew reporting to him including both Senior Drilling Supervisors and all the Drilling Supervisors. ${ }^{43}$

\footnotetext{
40 Email - Montara Platform Wells Morning Update dated 16th April 2009.

41 In giving evidence to the CoI, the Senior Drilling Supervisor claimed that he had told the Drilling Superintendent about the $16.5 \mathrm{bbl}$ returns seen at the end of the cementing operation and that it was the Drilling Supervisor who told him to pump the fluid back into the well, thereby creating the "wet shoe". The Col had no hesitation in dismissing this version of events (see Borthwick, 2010. Paragraphs 3.83-3.106).

42 Statutory Declaration of C.A. Wilson paragraph 12.
}

Importantly, this is a significant change in role from that of a technical expert in well design to the role of a manager. Sensemaking theory reminds us that the cues we see depend critically on our perception of our role (or organisational identity). In this case, there was perhaps an intention on the part of the organisation that the Drilling Superintendent maintain some technical oversight, but he seems to have a different understanding of the new role. He seems to have adopted an attitude to supervising the personnel that was based on providing advice when asked, rather than proactively providing input to the work that was being done. He goes on to say, "Although there was appropriate communication between [the Senior Drilling Supervisor] and me on 7 March 2009 there was information that I consider, with the benefit of hindsight, could have been given to me so that I would be better able to make decisions about what needed to be done in the face of the apparent failure of the float valve. In hindsight, the additional information required was about the quantity of fluids that were pumped back into the casing and the variation in the pressures whilst waiting on the cement to set." Further, "my post incident analysis indicates that the $95 / 8$ " casing shoe most probably did not form an adequate primary tested barrier however on the day with the information supplied to me, I had no reason to suspect that it was not an adequate barrier". ${ }^{4}$

Putting aside the question as to whether he had not received the information or had received the information and failed to read it, he seems to have conceptualised his role as one of giving advice when asked, rather than actively supervising or providing a level of specialist technical oversight of well integrity issues.

The Inquiry has highlighted one critical occasion on which the Senior Drilling Supervisor did seek technical advice from the Drilling Superintendent and yet such advice was not forthcoming. This was in the calculation of the volume of cement necessary to be pumped into the $\mathrm{H} 1$ well in order to meet the design parameters of height above the reservoir that are specified in the PTT Well Construction Standard. In fact, the calculation submitted by the Senior Drilling Supervisor for checking (and ultimately used as the basis for the volume of cement pumped into the well) was seriously incorrect and yet the Drilling Superintendent did not check the calculation or provide any response. ${ }^{45}$

This significant confusion over the role of senior management personnel with an apparently high level of technical knowledge was also seen in the decision not to reinstall the $95 / 8^{\prime \prime}$ PCCC after the cleaning of the threads on the $133 / 8^{\prime \prime}$ casing. In his statement, the Well Construction Manager (who was on the facility at the time) says that, based on the other barriers in place, "there was no compelling reason to re-install the $95 / 8^{\prime \prime}$ corrosion cap". ${ }^{46}$ Contrary to this, he told the Inquiry during the hearing that he had expected that the cap would be reinstalled once the cleaning work was complete and that when he discovered that it had not been installed he did not insist on the basis that "he did not want to give the impression to personnel on the rig that he was trying to teach them how to do their jobs". ${ }^{47}$ In fact, of course, it was the Well Construction Manager's role both to ensure that work was done in accordance with plans (and he apparently planned that the cap would be reinstated) and to ensure the technical robustness of activities undertaken. To leave a well barrier uninstalled for such a reason is clearly an abrogation of both the managerial and technical responsibilities of this role. The blowout occurred approximately 15 hours later.

Another source of an independent check on activities might have been the corporate HSE specialists. The Well Construction

\footnotetext{
43 Statutory Declaration of C.A. Wilson paragraph 16.

44 Statutory Declaration of C.A. Wilson paragraph 259 - emphasis added.

45 Borthwick, 2010. Paragraphs 3.158-3.165.

46 Statutory Declaration of C.N. Duncan paragraph 251.

47 Borthwick, 2010. Paragraph 3.187.
} 
Manager had overall responsibility for the development drilling activity. He reported to the Montara Project Manager, who reported to the CEO. ${ }^{48}$ Corporate HSE functions report via a separate line to the CEO and appear to have played no role in integrity assurance in drilling activity despite the statement from the Chief Operating Officer that the Well Construction Department works under the Corporate Safety Management System. ${ }^{49}$

Similar issues related to organisational design (that is, structure, roles, reporting lines related to technical specialists) have been highlighted in analyses of other accidents. Analysis of the circumstances surrounding the Texas City refinery accident (Hopkins, 2008) showed that those with technical responsibility for process safety issues were marginalized by the organisational structure. This left them unable to raise their concerns with senior management in any way that was effective in initiating action. Similarly, the report into the Columbia space shuttle disaster discussed attributes of organisational design related to the power and authority of technical specialists that could be expected to prevent such incidents from occurring again. In particular, the report called for (amongst other things) "a robust and independent program technical authority that has complete control over specifications and requirements, and waivers to them" (CAIB, 2003).

The situation at PTT seems to have been even more unsatisfactory in that there was no effective engineering input into well operations and no integrity assurance function operating in the organisation with regard to well activities at the time of the blowout. This further reinforces trial and error offshore as the primary method of organisational learning regarding drilling practices (as discussed in Section 5.1). These attitudes can be contrasted with those that HRO researchers tell us are necessary to avoid accidents in the long term, such as preoccupation with failure (Weick and Sutcliffe, 2001). Instead, these people as a group seem to have moved to an attitude that assumes everything is fine until proven otherwise. This attitude of trial and error learning in a high hazard environment such as offshore drilling makes the occurrence of a serious incident only a matter of time.

\subsection{Effective change management - rule compliance versus risk assessment}

The lack of specific direction from onshore management then apparently leaves work on the rig being done in accordance with PTT's written standards and other documentation. As the Chief Operating Officer says “... the PTTEPAA system relied upon the personnel involved in well construction following the requirements of the Well Construction Management System...it also relied on the expertise of the MODU facility operator's supervisory personnel and the PTTEPAA drilling supervisors to monitor and check that the MODU facility personnel complied with the drilling programs...." ${ }^{50}$ This seems to indicate that what senior PTT management expect from offshore personnel is compliance with written rules and standards.

The Well Construction Manager explains the role of one of the key documents, the PTT Well Construction Standard (WCS), in his statement,

"The purpose of the WCS is to provide standards for all aspects of well design, construction, testing, abandonment and intervention that involve a risk to safety, quality or integrity. The WCS are applicable to all aspects of well design, well construction, well servicing and well abandonment. We generated and prepared the WCS through a series of reviews and workshops with the well construction team. However, the WCS was not a prescriptive set of rules to cover every possible

\footnotetext{
48 See Statutory Declaration of A.C. Jacobs (revised) paragraphs 4, 17-23.

49 Statutory Declaration of A.C. Jacobs (revised) paragraph 4 and 26.

50 Statutory Declaration A.C. Jacobs (revised) paragraph 77.
}

scenario but includes processes to risk assess and manage scenarios not considered between document revisions". ${ }^{51}$

He is taking a rather different view of the role of the technical requirements (on such critical safety issues as well control barriers) contained in the WCS. This material has effectively been downgraded from something that requires mandatory compliance to playing the role of a guideline that can be varied based on a risk assessment. One example of how this was working in practice is the documentation regarding the change to the well design from cement plug to PCCCs.

As described in Section 4.2, various individuals have justified changing the written drilling plan to include PCCCs, despite the fact that this device is not listed as a well control barrier in the WCS. Arguments used by PTT drilling personnel in favour of the change include:

- PCCCs are better than cement plugs.

- PCCCs have the same functionality as other devices that are listed in the WCS so they are, in effect, approved.

- The WCS allows for two suspension options:

- Temporary suspension "where the MODU remains on location" and

- Long term suspension "when the MODU leaves the site. Wells must be suspended so that they can be abandoned with rig-less intervention to meet the standards below."

In the case of Montara, the MODU was leaving the site, but there was no plan to abandon the wells so PTT argued that it was reasonable to use the standards applicable to temporary suspension, even for the period when the MODU was elsewhere. ${ }^{52}$ Their point seems to be that the WCS does not allow for batch drilling i.e. the case where wells are suspended and the rig departs, knowing that it will return for more planned work. This is indeed a case where the rules may not be applicable and a risk assessment of the batch drilling case could have been used to develop a new range of acceptable well control barriers based on the risks involved.

Putting that aside, other claims about the functionality and effectiveness of the PCCCs are not supported by the information supplied from the manufacturer. The Drilling Superintendent says he sent the manufacturer's instructions offshore so that “. . . the caps could be installed as per the manufacturer's instructions. I assumed that those instructions would call for an in situ pressure test after installation and I did not note prior to sending out the manufacturer's instructions that they themselves did not call for the PCCCS to be pressure tested once installed." ${ }^{33}$ In fact, the Operating and Service Manual for the PCCCs explicitly states that they are not designed to operate as barriers against blowout and are only meant to be used on a well that has been plugged and secured. It seems likely that, in preparing the risk assessment on the proposed change (described in Section 4.2), the Drilling Superintendent did not read any of the material provided by the manufacturer for this critical safety device. $^{54}$

Hopkins (2010) has highlighted the interrelationship between risk assessment and rule compliance. He points out that rules are often based on risk assessments and that, as far as possible, risk assessments should be formulated into rules to assist end point decision makers such as those involved in operational drilling activities. He highlights other accidents where the temptation to risk assess one's way out of specific safety requirements has con-

\footnotetext{
51 Statutory Declaration of C.N. Duncan paragraph 43.

52 Statutory Declaration of C.A. Wilson paragraph 152 and statutory declaration of C.N. Duncan paragraph 159.

53 Statutory Declaration of C.A. Wilson paragraph 198

54 Borthwick, 2010. Paragraph 3.215.
} 
tributed to accidents, as appears to have been the case with Montara.

This section has proposed three ways in which organisational systems could have been improved to the point that the blowout may have been avoided. The common factor is maintaining an organisation-wide focus on well integrity issues driven by management constantly paying attention to them. Other decision making research in high hazard organisations (Hayes, 2009b) has highlighted the value of shared stories about past failures as a way of keeping alive the level of respect that is necessary in order to make effective decisions in these circumstances. It seems likely that a "fly on the wall" at PTT would not have heard such stories, but rather talk of operational priorities and cost savings.

\section{Regulatory implications}

The fundamental requirement of the type of goal setting regulation used throughout the offshore oil and gas industry in Australia is that operating companies must set their own standards based on the hazards and risks posed by their activities, and then, most importantly, do what they say they will do (Ayres and Braithwaite, 1992; Hood et al., 2004). In the case of Montara, this system failed. PTT failed to comply with its Well Construction Standards (WCS) in numerous ways including:

- failure to test the cemented casing shoe and subsequent reliance on this untested barrier,

- reliance on pressure containing corrosion caps (PCCCs) as a well barrier when these are not approved in the WCS,

- failure to install sufficient barriers to meet the requirements for long term suspension of the well when the West Atlas left the field, and

- failure to monitor completion fluid parameters to ensure overbalance and subsequent reliance on this unmonitored barrier during temporary suspension (when the West Atlas returned to the field).

The Montara Commission of Inquiry reported that "the regulatory regime was too trusting and that trust was not deserved." 55 To date, the primary regulatory response has been to change the body responsible for administering and enforcing the well integrity regulations from the state designated authorities to the National Offshore Petroleum Safety Authority. Perhaps the fundamental management problems seen at PTT require a different regulatory response - one that addresses directly the need for organisational competence and capacity.

A significant body of analysis has grown up based on the work of social scientists regarding the causes of specific disasters in complex socio-technical systems, for example, the loss of the space shuttle Challenger (Vaughan, 1996), the loss of US Black Hawk helicopters (Snook, 2000), the loss of the space shuttle Columbia (Starbuck and Farjoun, 2005), the explosion and fire at Exxon's Longford gas plant (Hopkins, 2000) and the BP Texas City Refinery fire (Hopkins, 2008). Formal investigations have included a social science perspective in addition to a review of more proximate technical issues, for example, the investigation into the storage tank fire at Buncefield (HSE Major Incident Investigation Board, 2008), the Baker Panel review of BP's US Refining Operations after the Texas City refinery fire (Baker, 2007), the review of the Columbia Investigation Board (CAIB, 2003) and the report of the National Commission following the Deepwater Horizon blowout (National Commission on the BP Deepwater Horizon Oil Spill and Offshore Drilling, 2011). These analyses rarely reveal new technical information

\footnotetext{
${ }^{55}$ Borthwick, 2010, p. 18.
}

regarding the causes of accidents but, rather, show that existing technical information has not been applied, usually for social, rather than technical, reasons.

Historically, goal setting, risk based regulation has taken a narrow technical perspective on causes of accidents. It is difficult to argue that a regulatory regime focussed on risk reduction can afford to ignore organisational issues. Some would argue no doubt that involvement in such a view of organisational activities is an imposition on the part of government but as Ayres and Braithwaite (1992, p. 4) assert, "The very behavio[u]r of an industry or the firms therein should channel the regulatory strategy to greater or lesser degrees of government intervention."

The Norwegian regulatory arrangements for the offshore oil and gas industry now include a requirement for organisations to promote a sound safety culture (Høivik et al., 2009). Perhaps it is time for other jurisdictions to take a similar step.

\section{Conclusions}

The individuals responsible for operational and management activities in drilling the Montara $\mathrm{H} 1$ well made a series of mistakes. Analysis to date has largely focussed on the apparent lack of judgement of those involved. This very narrow view focuses assessment of accident causation on technical competence as the key issue. This article has attempted to provide a broader consideration of the factors at play within PTT as an organisation. As with so many accidents in complex systems, the causes of the Montara blowout are closely linked to issues of organisational behaviours, driven ultimately by organisational priorities. The analysis suggests that active supervision of activities offshore, separation of technical integrity and management functions and better risk assessment of proposed changes may have been effective in preventing the blowout. There are clear lessons in the PTT situation for other organisations who manage complex, hazardous activities such as offshore drilling.

In order to ensure ongoing safe operations, organisations need both the competence and the capacity to identify the inevitable errors and also to do something about them in a timely manner. Organisational competence includes not only technical skills knowledge and experience, but also, critically, management competence sufficient to ensure that the inevitable technical errors are captured and corrected, before the cumulative results are catastrophic. Similarly, organisational capacity includes not just ensuring adequate resources, but also providing sufficient diversity of perspectives to ensure that technical integrity problems are identified despite the cost and schedule pressures that are everpresent in the offshore drilling industry.

Traditionally, regulation of offshore safety has focussed solely on the technical systems (both engineering and procedures) that need to be in place to prevent accidents. The Montara incident provides further weight to a growing body of evidence that safety regulation must venture into issues such as organisational culture and capacity if government is to meet societal expectations for accident prevention.

\section{References}

Argyris, C., 2004. Reasons and Rationalisations: The Limits to Organizational Knowledge. Oxford University Press, Oxford.

Ayres, I., Braithwaite, J., 1992. Responsive Regulation: Transcending the Deregulation Debate. Oxford University Press, New York.

Baker, J., 2007. The Report of the BP US Refineries Independent Safety Review Panel. Borthwick, D., 2010. Report of the Montara Commission of Inquiry.

Bourrier, M., 2011. The legacy of the high reliability organization project. Journal of Contingencies and Crisis Management, 19.

CAIB, 2003. Report of the Columbia Accident Investigation Board, vol. 1. 
Carroll, J.S., Rudolph, J., Hatakenaka, S., 2002. Learning from experience in highhazard organizations. In: Staw, B., Kramer, R. (Eds.), Research in Organizational Behavior. Elsevier Science, Oxford.

Cullen, L., 1990. The Public Inquiry into the Piper Alpha Disaster. HMSO, London. Dreyfus, H.L., Dreyfus, S.E., 1986. Mind over Machine. The Free Press, New York. Flyvbjerg, B., 2001. Making Social Science Matter: Why Social Inquiry Fails and How it Can Succeed Again. Cambridge University Press, Cambridge.

Hayes, J., 2009a. Incident reporting: a nuclear industry case study. In: Hopkins, A (Ed.), Learning from High Reliability Organisations. CCH, Sydney.

Hayes, J., 2009b. Operational decision-making. In: Hopkins, A. (Ed.), Learning from High Reliability Organisations. CCH, Sydney.

Høivik, D., Moen, B.E., Mearns, K., Haukelid, K., 2009. An explorative study of health safety and environment culture in a Norwegian petroleum company. Safety Science, 47.

Hollnagel, E., 2004. Barriers and Accident Prevention. Ashgate, Aldershot.

Hood, C., Rothstein, H., Baldwin, R., 2004. The Government of Risk: Understanding Risk Regulation Regimes. Oxford University Press, Oxford.

Hopkins, A., 2000. Lessons from Longford: The Esso Gas Plant Explosion. CCH, Sydney.

Hopkins, A., 2008. Failure to Learn: the BP Texas City Refinery Disaster. CCH, Sydney.

Hopkins, A., 2010. Risk-management and rule-compliance: decision making in hazardous industries. Safety Science. doi:10.1016/j.ssci.2010.07.014.

HSE Major Incident Investigation Board, 2008. Final Report - The Buncefield Incident 11 December 2005, Richmond, Surrey.
Izon, D., Danenberger, E.P., Mayes, M., 2007. Absence of fatalities in blowouts encouraging in MMS study of OCS incidents 1992-2006. Drilling Contractor.

Mills, J.H., 2003. Making Sense of Organizational Change. Routledge, New York.

National Commission on the BP Deepwater Horizon Oil Spill and Offshore Drilling, 2011. Deep Water: The Gulf Oil Disaster and the Future of Offshore Drilling, Report to the President.

Rasmussen, J., Svedung, I., 2000. Proactive Risk Management in a Dynamic Society. Swedish Rescue Services Agency, Karlstad.

Reason, J., 1997. Managing the Risks of Organizational Accidents. Ashgate, Aldershot.

Snook, S.A., 2000. Friendly Fire: The Accidental Shootdown of US Black Hawks over Northern Iraq. Princeton University Press, Princeton.

Starbuck, W.H., Farjoun, M., 2005. Organising at the Limit: Lessons from the Columbia Disaster. Blackwell Publishing, Oxford.

Vaughan, D., 1996. The Challenger Launch Decision: Risky Technology, Culture and Deviance at NASA. University of Chicago Press, Chicago.

Weick, K.E., 1993. The collapse of sensemaking in organizations: the Mann Gulch disaster. Administrative Science Quarterly 38, 628-652.

Weick, K.E., 1995. Sensemaking in Organizations. Sage Publications, Thousand Oaks. Weick, K.E., 2001. Making Sense of the Organization. Blackwell Business, Oxford.

Weick, K.E., Sutcliffe, K.M., 2001. Managing the Unexpected: Assuring High Performance in an Age of Complexity. Jossey-Bass, San Francisco.

Weick, K.E., Sutcliffe, K.M., Obstfeld, D., 2005. Organizing and the process of sensemaking. Organization Science 16, 409-421. 